\title{
Penerapan Analisis Multidimensional Scaling (MDS) Pada Pemetaan Kabupaten/Kota di Provinsi Sulawesi Tengah Berdasarkan Indikator Tenaga Kesehatan
}

\section{(Application of Multidimensional Scaling (MDS) Analysis to the Mapping of Districts/Cities in Central Sulawesi Province Based on Indicators of Health Workers)}

\author{
Mira Bela Islami ${ }^{1 *}$, Rais ${ }^{1}$, Lilies Handayani ${ }^{1}$ \\ ${ }^{1}$ Program Studi Statistika, Jurusan Matematika, Fakultas MIPA, Universitas Tadulako Jl. Soekarno Hatta Km 9 Tondo \\ Palu Sulawesi Tengah 94118
}

Keywords: Multidimensional Scaling, Mapping, Health Worker.

Keywords: Multidimensional Scaling, Pemetaan, Tenaga Kesehatan.

* Coresponding Author : miraislami01@gmail.com

\begin{abstract}
Health workers is any person who dedicates theirself in the health sector and have knowledge, skills and authority to make health efforts. The lack number of health workers or the univen distribution of health workers is a problem that often occurs in each region. This research will use the method of multidimensional scaling in mapping districts / cities in Central Sulawesi Province based on indicators of health workers. The results obtained are formed in to 4 groups of districts/cities that have similarities among its members but different from other groups. In the group 1 is Palu, Group 2 contained Parigi Moutong districts. In the group 3 consists of Banggai, Poso, Sigi and Toli-Toli Districts. In the group 4 consist of Tojo Una-una, Morowali, Donggala, Morowali Utara, Banggai Laut, Buol, and Banggai Islands. Stress value obtained is $4.354 \%$ and the value of $R^{\wedge} 2$ is $99.568 \%$, which indicates that the data used can be mapped properly.
\end{abstract}

\footnotetext{
Abstrak

Tenaga kesehatan adalah setiap orang yang mendedikasikan dirinya dalam bidang kesehatan serta memiliki pengetahuan, keterampilan, serta wewenang untuk melakukan upaya kesehatan. Jumlah tenaga kesehatan yang kurang atau pun distribusi tenaga kesehatan yang tidak merata menjadi masalah yang sering terjadi di setiap wilayah. Pada penelitian ini akan digunakan metode multidimensional scaling dalam memetakan kabupaten/kota di Provinsi Sulawesi Tengah berdasarkan indikator tenaga kesehatan. Hasil yang diperoleh adalah terbentuk 4 kelompok kabupaten/kota yang memiliki kemiripan antar anggota nya namun berbeda dengan kelompok lain. Pada kelompok 1 terdapat Kota Palu, Kelompok 2 terdapat Kabupaten Parigi Moutong. Pada kelompok 3 terdiri atas Kabupaten Banggai, Poso, Sigi, dan Toli-Toli. Pada kelompok 4 terdiri atas Kabupaten Tojo Una-una, Morowali, Donggala, Morowali Utara, Banggai Laut, Buol, dan Banggai Kepulauan. Dari hasil penelitian diperoleh nilai stress $4,354 \%$ serta nilai $R^{\wedge} 2$ sebesar 99,568\%, hal ini menunjukkan bahwa data yang digunakan dapat dipetakan dengan baik.
} 


\section{Latar Belakang}

Menurut WHO, tenaga kesehatan adalah setiap orang yang memiliki pengetahuan dan kewenangan serta kegiatan pokoknya ditujukan untuk meningkatkan pembangunan kesehatan. Mereka terdiri atas orangorang yang memberikan pelayanan kesehatan seperti dokter, perawat, apoteker, teknisi laboratoium, manajemen, serta tenaga pendukung bagian keuangan, sopir, dan lain sebagainya (WHO, 2006).

Tenaga kesehatan sebaga kunci utama, memberikan kontribusi hingga $80 \%$ dalam keberhasilan pembangunan kesehatan. Namun pada kenyataannya dalam laporan WHO tahun 2006, Indonesia merupakan salah satu dari 57 negara yang mengalami krisis SDM kesehatan, baik jumlahnya yang kurang maupun distribusinya yang belum merata (Kementrian Kesehatan RI, 2011).

Provinsi Sulawesi Tengah merupakan salah satu provinsi di Indonesia yang mengalami krisis tenaga kesehatan dari segi pendistribusiannya. Pada tahun 2016 jumlah tenaga kesehatan di masing-masing kabupaten/kota di Provinsi Sulawesi Tengah masih belum merata. Hal ini ditunjukan dengan jumlah dokter spesialis di Kabupaten Morowali Utara hanya 1 orang sedangkan di Kabupaten Poso berjumlah 18 orang dan Kota Palu mencapai 71 orang. Selain itu pada jenis tenaga kefarmasian di kabupaten Morowali Utara berjumlah 12 orang sedangkan pada kabupaten Morowali mencapai 60 orang (BPS Provinsi Sulawesi Tengah, 2017).

Salah satu langkah awal dalam menangani tidak meratanya tenaga kesehatan adalah dengan melakukan pemetaan tenaga kesehatan di masing-masing wilayah, yang dapat dijadikan sebagai dasar perencanaan kebutuhan tenaga kesehatan. Pemetaan sendiri dapat dilakukan dengan menggunakan analisis Multivariat. Analisis multivariat berhubungan dengan metodemetode statistik yang secara bersama-sama melakukan analisis terhadap lebih dari dua variabel (baik variabel bebas maupun variabel terikat) pada setiap objek atau individu (Santoso, 2017).

Pada hakekatnya analisis multivariat dapat dibagi menjadi dua kelompok yaitu analisis dependensi dan analisis interdependensi. Analisis dependensi adalah analisis untuk mengetahui hubungan antara variabel independen (bebas) dan variabel dependen (terikat), sedangkan analisis interdependensi adalah analisis untuk mengetahui hubungan antar variabel independen (bebas) (Mattjik dan Sumertajaya, 2011).

Terdapat beberapa jenis analisis pada analisis interdependensi, salah satunya adalah analisis multidimensional scaling. Analisis multidimensional scaling (MDS) merupakan salah satu teknik multivariat yang berhubungan dengan pembuatan peta yang dapat digunakan untuk menggambarkan posisi suatu objek dengan objek lain berdasarkan nilai kemiripan antar objek tersebut. MDS terbagi menjadi dua jenis, yaitu MDS metrik jika data berskala interval atau rasio dan MDS non metrik jika data berskala nominal atau ordinal (Mattjik dan Sumertajaya, 2011).

Pemetaan menggunakan analisis multidimensional scaling pernah dilakukan oleh Nahar (2016) mengenai pemetaan saranana kesehatan di Provinsi Jawa Barat. Dari hasil pemetaan tersebut terdapat tiga kelompok kota yang memiliki kemiripan antar anggotanya namun berbeda dengan kelompok lainnya. Tiap kelompok yang terbentuk memiliki kemiripan dari jumlah fasilitas sarana kesehatan.

Berdasarkan uraian diatas, pada penelitian ini akan dilakukan pemetaan kabupaten/kota di Provinsi Sulawesi Tengah menggunakan analisis multidimensional scaling metrik 2 dimensi berdasarkan beberapa indikator tenaga kesehatan.

\section{Bahan dan Metode}

Data yang digunakan dalam penelitian ini merupakan data sekunder yang diperoleh dari Dinas Kesehatan Daerah Provinsi Sulawesi Tengah pada tahun 2017. Objek pada penelitian ini terdiri atas 13 kabupaten/kota yang terdapat di Provinsi Sulawesi Tengah. Adapun variabel-variabel yang digunakan yaitu
a. Tenaga kebidanan $\left(X_{1}\right)$
b. Tenaga keperawatan $\left(X_{2}\right)$
c. Tenaga kesehatan lingkungan $\left(X_{3}\right)$
d. Tenaga kesehatan masyarakat $\left(X_{4}\right)$
e. Dokter Umum $\left(X_{5}\right)$

Metode yang digunakan pada penelitian ini adalah analisis multidimensional scaling 2 dimensi. Tahapan analisis yang akan digunakan pada penelitian ini adalah sebagai berikut :

1. Pengambilan data

2. Melakukan standarisasi data

3. Menghitung nilai kemiripan antar objek menggunakan rumus euclidean

4. Menentukan matriks product scalar $\boldsymbol{B}$

5. Menghitung nilai eigen dan vektor eigen

6. Menentukan titik koordinat

7. Membentuk peta persepsi

8. Menghitung Disparities matriks

9. Menghitung nilai stress dan $R^{2}$

10.Menentukan karakteristik tiap kelompok

11. Interpretasi dan Kesimpulan 


\section{Hasil dan Pembahasan}

Berikut merupakan proses analisis multidimensional scaling metrik dalam memetakan kabupaten/kota di Provinsi Sulawesi Tengah berdasarkan indikator tenaga kesehatan.

\section{Standarisasi Data}

Standarisasi data perlu dilakukan pada penelitian ini karena terdapat perbedaan satuan ukuran yang lebar pada data. Berikut perhitungan standarisasi data :

Standarisasi data jumlah tenaga kebidanan di Kabupaten Banggai Kepulauan:

$$
\begin{aligned}
z & =\frac{x_{i}-\bar{x}_{1}}{s_{1}} \\
& =\frac{173-349,692}{180,979} \\
& =-0,976
\end{aligned}
$$

Standarisasi data jumlah tenaga keperawatan di Kabupaten Banggai Kepulauan:

$$
\begin{aligned}
z & =\frac{x_{i}-\bar{x}_{2}}{s_{2}} \\
& =\frac{209-524}{436,629} \\
& =-0,721
\end{aligned}
$$

Perhitungan standarisasi data untuk data lainnya dapat dilakukan dengan cara yang sama sehingga menghasilkan data hasil standarisasi yang dapat digunakan untuk memetakan kabupaten/kota di Provinsi Sulawesi Tengah.

Tabel 1. Koordinat Stimulus

\begin{tabular}{lcc}
\hline \multirow{2}{*}{ Kabupaten/Kota } & \multicolumn{2}{c}{ Dimensi } \\
\cline { 2 - 3 } Banggai & 1 & 2 \\
Kepulauan & 1,0747 & 0,1349 \\
Banggai & $-0,3909$ & 0,1379 \\
Banggai Laut & 1,1754 & 0,1616 \\
Morowali & 0,7262 & $-0,0288$ \\
Morowali Utara & 0,7606 & 0,0233 \\
Poso & 0,1436 & $-0,5635$ \\
Donggala & 0,6259 & 0,3314 \\
Toli-Toli & $-0,1216$ & $-0,3396$ \\
Buol & 0,9583 & 0,2364 \\
Parigi Moutong & $-1,9825$ & $-1,8017$ \\
Tojo Una-Una & 0,3285 & 0,4203 \\
Palu & $-3,2907$ & 1,3779 \\
Sigi & $-0,0076$ & $-0,0901$ \\
\hline
\end{tabular}

Menghitung nilai kemiripan

Kemiripan antar objek dapat diukur dengan menggunakan ukuran jarak. Menentukan nilai kemiripan antar objek pada analisis multidimensional scaling menggunakan rumus jarak euclidean. Jarak euclidean digunakan karena data tenaga kesehatan di Provinsi Sulawesi Tengah memiliki satuan data yang sama. Perhitungan jarak euclidean menggunakan rumus sebagai berikut :

$$
d_{i j}=\sqrt{\sum_{k=1}^{p}\left(x_{i k}-x_{j k}\right)^{2}}
$$

Sehingga diperoleh nilai kemiripan antar objek berukuran $13 \times 13$ sebagai berikut :

$\boldsymbol{D}=\left[\begin{array}{lllll}\mathbf{0 , 0 0 0} & \mathbf{2 , 2 2 4} & \mathbf{0 , 2 0 2} & \cdots & \mathbf{1 , 8 2 0} \\ \mathbf{2 , 2 2 4} & \mathbf{0 , 0 0 0} & \mathbf{2 , 3 7 3} & \cdots & \mathbf{1 , 2 7 3} \\ \mathbf{0 , 2 0 2} & \mathbf{2 , 3 7 3} & \mathbf{0 , 0 0 0} & \cdots & \mathbf{1 , 9 4 2} \\ \mathbf{0 , 7 8 2} & \mathbf{1 , 8 4 3} & \mathbf{0 , 8 4 1} & \cdots & \mathbf{1 , 1 9 8} \\ \mathbf{0 , 5 3 9} & \mathbf{1 , 7 5 6} & \mathbf{0 , 6 6 6} & \cdots & \mathbf{1 , 4 2 8} \\ \mathbf{1 , 7 8 2} & \mathbf{1 , 3 8 8} & \mathbf{1 , 9 3 6} & \cdots & \mathbf{1 , 1 5 5} \\ \mathbf{1 , 0 7 7} & \mathbf{1 , 8 9 4} & \mathbf{1 , 1 7 6} & \cdots & \mathbf{1 , 1 4 1} \\ \mathbf{2 , 0 6 4} & \mathbf{1 , 3 2 7} & \mathbf{2 , 2 2 2} & \cdots & \mathbf{1 , 0 6 6} \\ \mathbf{0 , 3 3 0} & \mathbf{2 , 0 7 7} & \mathbf{0 , 4 4 5} & \cdots & \mathbf{1 , 7 5 2} \\ \mathbf{5 , 4 3 6} & \mathbf{3 , 7 9 6} & \mathbf{5 , 5 8 1} & \cdots & \mathbf{3 , 9 5 4} \\ \mathbf{1 , 2 5 5} & \mathbf{1 , 4 1 6} & \mathbf{1 , 3 7 0} & \cdots & \mathbf{0 , 9 9 9} \\ \mathbf{6 , 7 5 4} & \mathbf{4 , 7 3 1} & \mathbf{6 , 8 8 5} & \cdots & \mathbf{5 , 3 9 1} \\ \mathbf{1 , 8 2 0} & \mathbf{1 , 2 7 3} & \mathbf{1 , 9 4 2} & \cdots & \mathbf{0 , 0 0 0}\end{array}\right]$

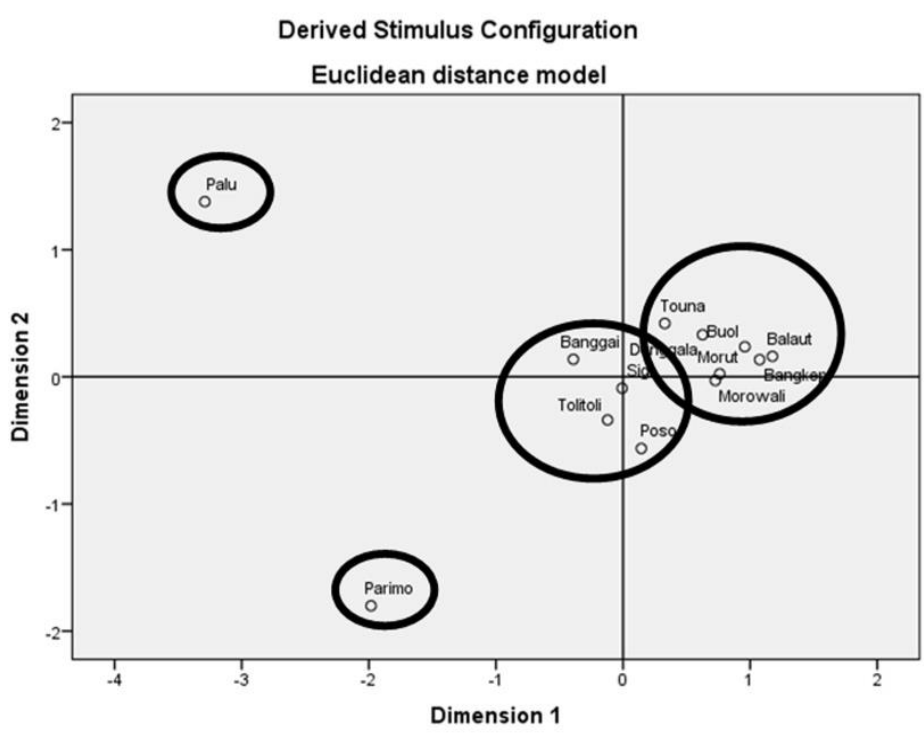

Gambar 1. Peta Persepsi

\section{Matriks product scalar B}

Menentukan matriks product scalar $\boldsymbol{B}$ dapat dilakukan menggunakan proses double centering menggunakan rumus sebagai berikut :

$\boldsymbol{B}=\boldsymbol{H} \boldsymbol{A} \boldsymbol{H}=\left(\boldsymbol{I}-\frac{1}{n} \boldsymbol{\delta}\right) \boldsymbol{A}\left(\boldsymbol{I}-\frac{1}{n} \boldsymbol{\delta}\right)$ 
sehingga diperoleh matriks product scalar $\boldsymbol{B}$ berukuran $13 \times 13$ sebagai berikut :

$$
\boldsymbol{B B}=\left[\begin{array}{ccccc}
2,665 & -0,793 & 2,900 & \cdots & -0,143 \\
-0,793 & 0,697 & -0,879 & \cdots & -0,280 \\
2,900 & -0,879 & 3,176 & \cdots & -0,117 \\
1,681 & -0,695 & 1,889 & \cdots & 0,118 \\
1,879 & -0,502 & 2,058 & \cdots & -0,147 \\
0,191 & -0,167 & 0,160 & \cdots & -0,039 \\
1,479 & -0,719 & 1,623 & \cdots & 0,256 \\
-0,427 & -0,162 & -0,509 & \cdots & -0,017 \\
2,407 & -0,679 & 2,617 & \cdots & -0,225 \\
-5,355 & 1,229 & -5,899 & \cdots & 0,451 \\
0,905 & -0,294 & 1,010 & \cdots & 0,043 \\
-7,389 & 3,243 & -8,028 & \cdots & -0,263 \\
-0,143 & -0,280 & -0,117 & \cdots & 0,363
\end{array}\right]
$$

\section{Koordinat Stimulus dan Peta Persepsi}

Koordinat stimulus merupakan titik-titik koordinat tiap kabupaten/kota yang selanjutnya akan digambarkan melalui sebuah peta atau bidang koordinat. Koordinat stimulus diperoleh dengan mengalikan nilai eigen dengan vektor eigen.

Berikut merupakan koordinat stimulus 2 dimensi yang diperoleh :

Koordinat Stimulus 2 dimensi memiliki arti terdapat 2 dimensi pada bidang koordinat yaitu sumbu $x$ dan sumbu $y$. Berdasarkan koordinat stimulus pada Tabel 1, selanjutnya dibentuk peta persepsi sebagai berikut :

Berdasarkan Gambar 1 dan Gambar 2 diketahui bahwa terbentuk 4 kelompok kabupaten/kota berdasarkan indikator tenaga kesehatan di Provinsi Sulawesi Tengah. Pada kelompok 1 terdapat Kota Palu yang ditandai dengan warna merah, pada kelompok 2 terdapat Kabupaten Parigi Moutong yang ditandai dengan warna hijau, pada kelompok 3 terdapat Kabupaten Banggai, Poso, Toli-toli, dan Sigi yang ditandai dengan warna kuning. Pada kelompok 4 terdiri atas Kabupaten Tojo Una-una, Morowali, Donggala, Morowali Utara, Banggai Laut, Buol, dan Banggai Kepulauan yang ditandai dengan warna biru. Berdasarkan pengelompokkan tersebut dapat diketahui bahwa Kota Palu dan Kabupaten Parigi Moutong tidak memiliki kemiripan dengan kabupaten lain.

Tabel 2. Nilai Stress dan $R^{2}$

\begin{tabular}{cc}
\hline Stress & $R^{2}$ \\
\hline $4,354 \%$ & $99,568 \%$ \\
\hline
\end{tabular}

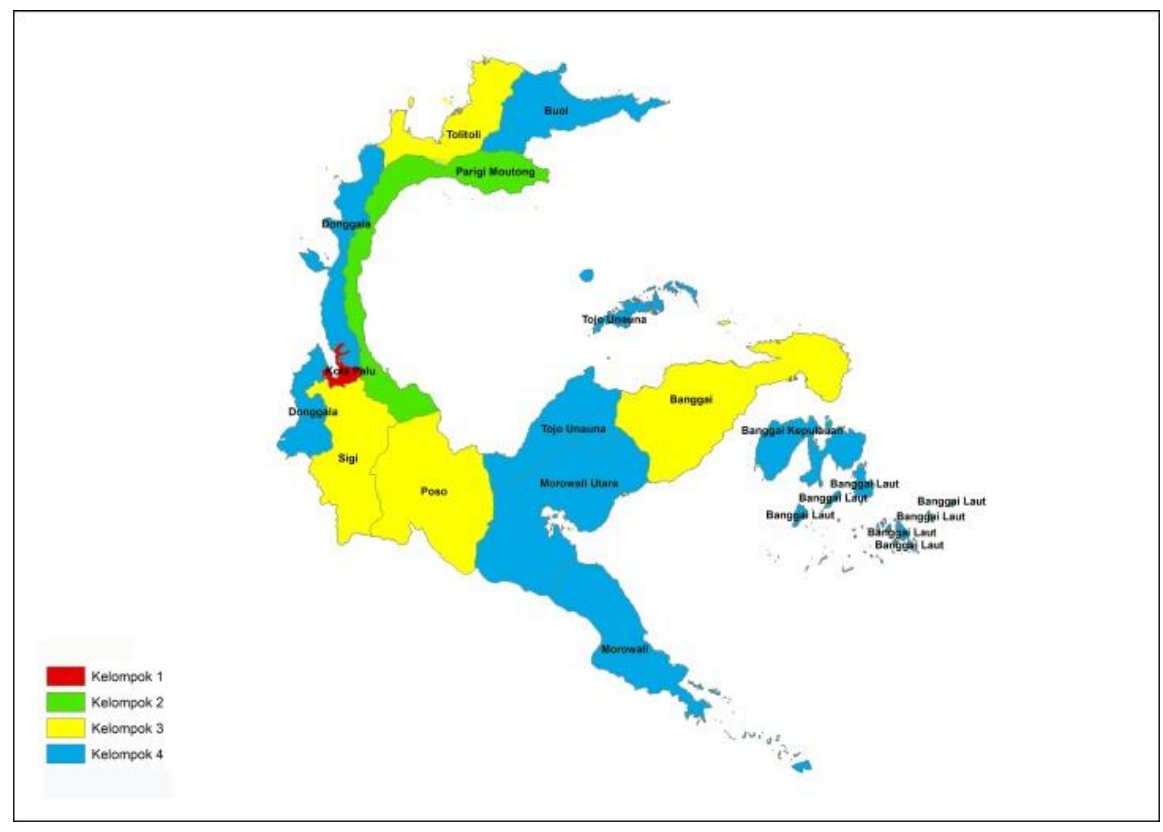

Gambar 2. Peta Kelompok

\section{Nilai stress dan $\boldsymbol{R}^{2}$}

Langkah selanjutnya pada analisis multidimensional scaling adalah menentukan nilai stress dan $R^{2}$ untuk mengetahui ketepatan jarak dari peta persepsi yang terbentuk.

Berdasarkan Tabel 2, dapat diketahui bahwa nilai stress yang diperoleh sebesar $4,354 \%$ masuk dalam kategori sangat baik, sehingga dapat disimpulkan jika data indikator tenaga kesehatan di Provinsi Sulawesi Tengah cocok digunakan untuk proses analisis multidimensional scaling. Nilai $R^{2}$ yang diperoleh sebesar 99,568\% menandakan bahwa data yang digunakan dapat dipetakan dengan baik. 


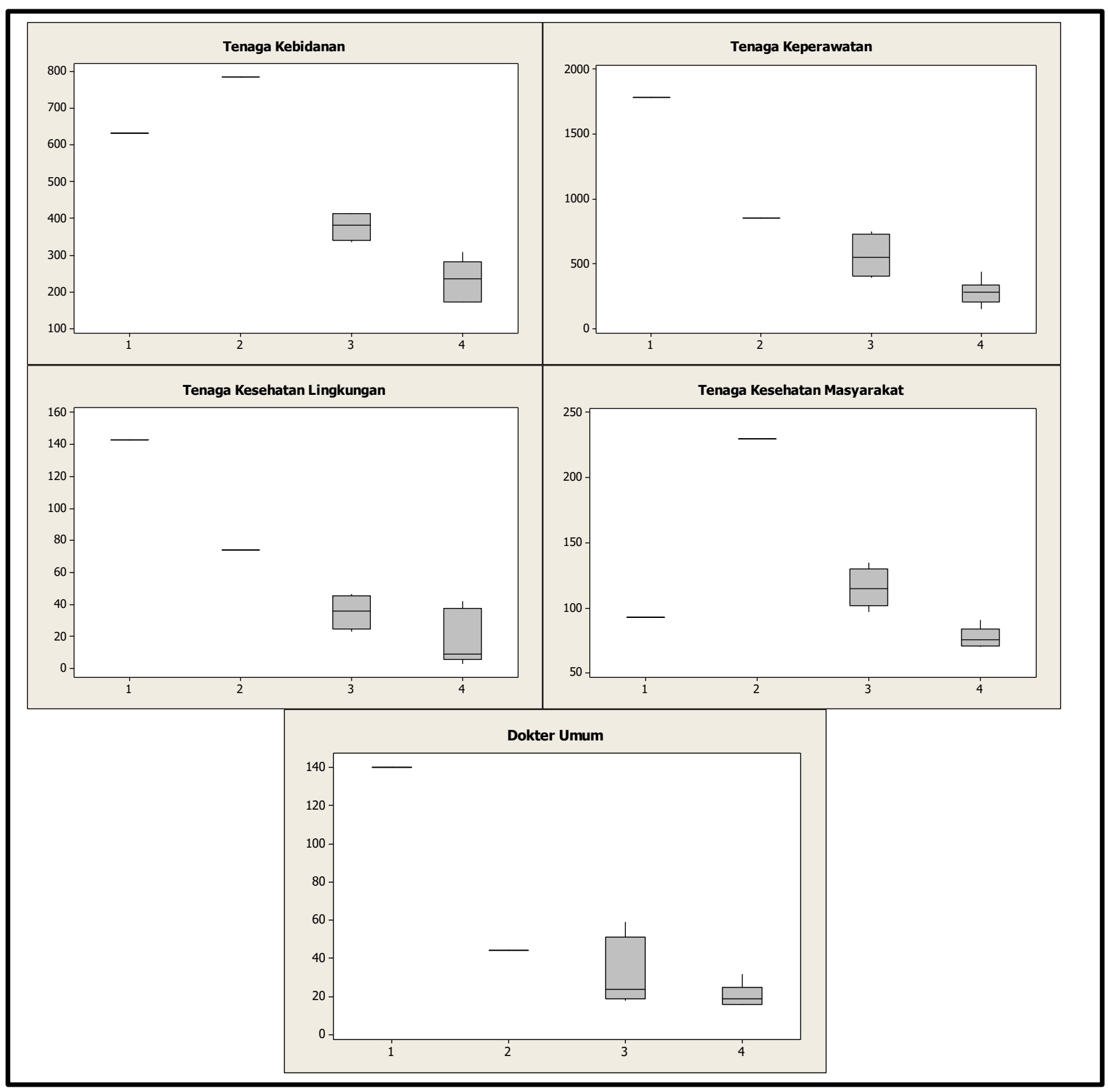

Gambar 3. Karakteristik Tiap Kelompok

\section{Karakteristik tiap kelompok}

Berdasarkan Gambar 3 dapat diketahui karakteristik dari masing-masing kelompok yang terbentuk. Karakteristik kelompok 1 yaitu memiliki jumlah tenaga keperawatan, tenaga kesehatan lingkungan, dan dokter umum terbanyak dibandingkan dengan kelompok lain. Namun pada jenis tenaga kesehatan masyarakat jumlahnya masih rendah dibandingkan dengan kelompok 2 dan kelompok 3.

Kelompok 2 yaitu Kabupaten Parigi Moutong memiliki karakteristik jumlah tenaga kesehatan paling stabil dibandingkan dengan kelompok lain. Pada jenis tenaga kebidanan dan tenaga kesehatan masyarakat Kabupaten Parigi Moutong memiliki jumlah tenaga kesehatan terbanyak dibandingkan kelompok lain.

Kelompok 3 memiliki karakteristik jumlah tenaga kesehatan terendah kedua dibandingkan dengan kelompok lain. Pada kelompok 4 rata-rata jumlah tenaga kesehatan paling rendah dibandingkan dengan kelompok lainnya.

\section{Ucapan Terimakasih}

Penulis mengucapkan terima kasih yang sebesarbesarnya kepada pihak Dinas Kesehatan Daerah 
Provinsi Sulawesi Tengah yang telah memperkenankan penulis untuk mengambil data tenaga kesehatan guna penyelesaian penelitian ini.

\section{Daftar Pustaka}

BPS Provinsi Sulawesi Tengah. 2017. Provinsi Sulawesi Tengah Dalam Angka. Sulawesi Tengah : BPS Provinsi Sulawesi Tengah.

Kementrian Kesehatan RI. 2011. Rencana Pengembangan Tenaga Kesehatan Tahun 2011-2025. Jakarta: Kementrian Kesehatan RI.
Mattjik, A. A., Sumertajaya, I. M. 2011. Sidik Peubah Ganda Dengan Menggunakan SAS. Bogor:IPB Press

Nahar, Julita. 2016. Penerapan Metode Multidimensional Scaling dalam Pemetaan Sarana Kesehatan di Jawa Barat, Jurnal Matematika Integratif, Vol. 12 : 43-50.

Santoso, S. 2017. Statistik Multivariat dengan SPSS. Jakarta : PT Elex Media Komputindo.

World Health Organization (WHO). 2006. The World Health Report 2006 : Working Together for Health. Geneva : World Health Organization. 